\section{'Leprechaun' Aglaonema}

\author{
Richard J. Henny ${ }^{1,2}$ and J. Chen ${ }^{1}$
}

University of Florida, Institute of Food and Agricultural Science, MidFlorida Research and Education Center, 2725 Binion Road, Apopka, FL 32703

Additional index words. Chinese evergreen, foliage plant production, plant breeding

The genus Aglaonema (family Araceae), commonly referred to as Chinese evergreens, has been an important tropical foliage crop since the 1930s (Smith and Scarborough, 1981). The first commercial Aglaonema cultivars were plants collected from their native tropical habitats, propagated, and sold as ornamentals. Plant breeding research to induce Aglaonema flowering (Henny, 1983) and to control pollination (Henny, 1985) made hybrid seed production protocols available. These breeding innovations led to the introduction of many new Aglaonema hybrid cultivars in the past 20 years by both public and private breeders worldwide. Ten Aglaonema cultivars have been released by the Foliage Plant Breeding Program at the Mid-Florida Research and Education Center in Apopka, FL, and have become commercially successful (Henny and Chen, 2001, 2008, 2009, 2010; Henny et al., 1988, 1992a, 1992b, 2003, 2008). We here describe 'Leprechaun', the eleventh Aglaonema cultivar to be developed and released.

\section{Origin}

Aglaonema 'Leprechaun' is a whole stem mutation found in a large population of Aglaonema $\times$ 'Silver Bay'. The mutant was initially elected as a result of its small, rounded plant form. It exhibited the same foliar variegation pattern as the parent Aglaonema $\times$ 'Silver Bay' but it was a dwarf and more highly branched compared with the parent plant. Aglaonema 'Leprechaun' was isolated, propagated by tip cuttings, and evaluated during a 3-year period, after which the mutation was determined to be stable and suitable as a new cultivar.

\section{Description}

Aglaonema 'Leprechaun' has a compact and symmetrically rounded plant habit. New leaves are initially upright and then arch outwardly and downwardly with development. Average mature leaf length is $\approx 20 \mathrm{~cm}$ and width is $\approx 7 \mathrm{~cm}$. Plants branch well, averaging over 10 basal shoots per cutting. In contrast, the mean canopy height of 'Silver

Received for publication 2 Mar. 2011. Accepted for publication 24 Apr. 2011.

${ }^{1}$ Professors.

${ }^{2}$ To whom reprint requests should be addressed; e-mail hennyrjz@ufl.edu.
Bay' is $33 \mathrm{~cm}$ versus a $55-\mathrm{cm}$ canopy width, its leaves average $30 \mathrm{~cm}$ in length and $11.5 \mathrm{~cm}$ in width, and plants average 3.5 basal shoots (Henny et al., 1992a).

The color descriptions that follow are based on The Royal Horticultural Society color chart (Royal Horticultural Society, 1995). The upper surfaces of mature, fully expanded leaves are yellow-green 147A to green 137A. The center area of the leaf is grayed-green 191B-C and extends out from the midrib toward the leaf edge more than half way on each side. The midrib itself is grayed-green 191A. The primary veins are grayed-green 191B-C. The lower surface of fully expanded leaves is yellow-green 147B. The lower surface midrib color is yellow-green $147 \mathrm{C}$ and the lower surface veination is yellow-green 147B. The overall petiole color is yellow-green $147 \mathrm{C}-\mathrm{D}$, whereas the petiole area adjacent to the stem is white $155 \mathrm{C}$. Color of the inner petiole wing is yellow-green 147D, whereas the outer petiole wing surface is lighter yellow-green $147 \mathrm{C}-\mathrm{D}$.

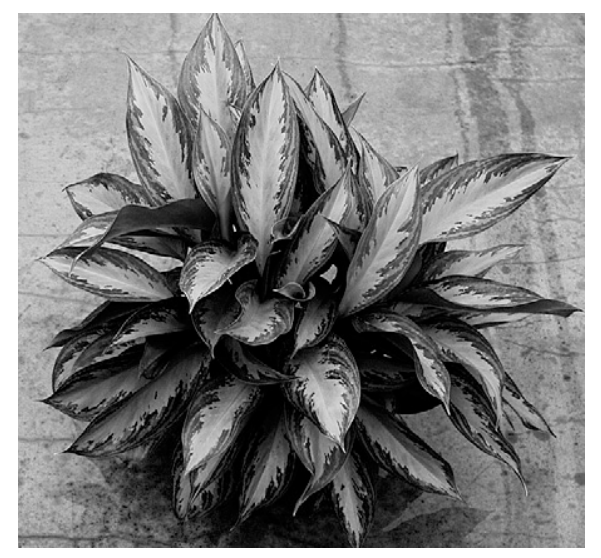

Fig. 1. Aglaonema 'Leprechaun' grown in a 1.6-L pot showing dense basal-branching habit. This plant was grown from a single rooted cutting and was photographed after being greenhousegrown for 9 months.
The petiole wing area adjacent to the stem is white 155C (Fig. 1).

\section{Performance}

Growth tests were initiated using 12- to $15-\mathrm{cm}$ long tip cuttings that held three to four leaves each. Cuttings were harvested from Aglaonema 'Leprechaun' stock plants grown in a shaded greenhouse and stuck in 50-celled trays containing Fafard \#2 Mix (Conrad Fafard, Inc., Agawam, MA; 55\% Canadian peat: $25 \%$ perlite: $20 \%$ vermiculite). The cuttings were placed inside a propagation tent (maximum irradiance of $80 \mu \mathrm{mol} \cdot \mathrm{m}^{-2} \cdot \mathrm{s}^{-1}$ ) for 8 weeks. The rooted cuttings were allowed to acclimatize for 2 additional weeks. At that time, 30 uniform rooted liners were selected and potted into 1.6-L pots using the same Fafard \#2 soil mix. Plants were grown in a randomized block experimental design in a shaded greenhouse under a maximum irradiance of 125 $\mu \mathrm{mol} \cdot \mathrm{m}^{-2} \cdot \mathrm{s}^{-1}$ in a natural photoperiod and a temperature range of 15 to $34^{\circ} \mathrm{C}$. Plants were grown using 3,5 , or $7 \mathrm{~g}$ per container of Nutricote Plus 18N-2.6P-6.6K (Chisso-Asahi Fertilizer Co., Ltd., Tokyo, Japan). Ten plants per each fertilizer treatment were grown in a completely randomized design for 9 months. Plants were hand-watered as necessary and fertilizer was reapplied every 3 months.

Data recorded at termination of the study included canopy height, canopy width, length and width of largest leaf, number of basal shoots, and a visual quality rating where $1=$ poor; 2 = fair (not saleable); 3 = acceptable (saleable); 4 = good quality; and $5=$ excellent quality. Finished plants were moved into an interior growth room for 3 months under a light level of $25 \mu \mathrm{mol} \cdot \mathrm{m}^{-2} \cdot \mathrm{s}^{-1}$ for $12 \mathrm{~h}$ daily at a constant $24{ }^{\circ} \mathrm{C}$. A second visual quality rating was measured after 3 months in the interior growth room conditions. Data were analyzed using analysis of variance procedures of the SAS program (SAS Institute Inc., Cary, NC).

\section{Results}

Aglaonema 'Leprechaun' grown in 1.6-L pots reached marketable size in 9 months. There were no significant differences in canopy height, canopy width, pulled-up height, leaf width, and number of basal shoots and plant quality between fertilizer levels (Table $1)$. There was a significant linear decrease in leaf length as fertilizer levels increased; however, the differences had no visual effect on

Table 1. Canopy height and width, length and width of largest leaf, number of basal shoots, and visual quality of Aglaonema 'Leprechaun' after 9 months' growth in 1.6-L pots.

\begin{tabular}{|c|c|c|c|c|c|c|}
\hline \multirow{2}{*}{$\begin{array}{l}\text { Nutricote } \\
\text { g/pot/3 months }\end{array}$} & \multicolumn{2}{|c|}{ Canopy } & \multicolumn{2}{|c|}{ Largest leaf } & \multirow{2}{*}{$\begin{array}{l}\text { No. basal } \\
\text { shoots }\end{array}$} & \multirow{2}{*}{$\begin{array}{l}\text { Visual } \\
\text { quality }^{\mathrm{z}}\end{array}$} \\
\hline & $\mathrm{Ht}(\mathrm{cm})$ & Width $(\mathrm{cm})$ & Length $(\mathrm{cm})$ & Width $(\mathrm{cm})$ & & \\
\hline 3 & 23.6 & 38.8 & 20.1 & 7.6 & 11.1 & 4.8 \\
\hline 5 & 22.8 & 39.1 & 19.5 & 7.2 & 10.1 & 4.5 \\
\hline 7 & 22.6 & 36.6 & 18.7 & 7.0 & 10.6 & 4.5 \\
\hline Significance $^{\mathrm{y}}$ & NS & NS & $\mathrm{L}^{*}$ & NS & NS & NS \\
\hline
\end{tabular}

${ }^{\mathrm{z}}$ Visual quality where 1 = poor, 2 = fair, 3 = saleable, 4 = good, and 5 = excellent quality.

${ }^{\mathrm{y}}$ Regression analysis in which $\mathrm{NS}=$ non-significant, $\mathrm{L}^{*}=$ linear significance at $5 \%$ level. 
appearance or quality. Plant quality rating averaged good to excellent at all nutritional levels. After 3 months of interior room testing, all plants graded out as excellent (data not presented).

\section{Availability}

Aglaonema 'Leprechaun' is trademarked and patented by the U.S. Patent and Trademark Office (PP 19,714). Plant patent rights are assigned to the University of Florida, Board of Trustees. Stock plants will be released under license to Florida growers for propagation and the variety is intended for commercial producers growing finished plants in 1.6- or 3.9-L containers. Inquiries regarding licensing may be sent to Florida
Foundation Seed Producers, Inc., P.O. Box 110200, Gainesville, FL 32611.

\section{Literature Cited}

Henny, R.J. 1983. Flowering of Aglaonema commutatum 'Treubii' following treatment with gibberellic acid. HortScience 18:374.

Henny, R.J. 1985. In vivo pollen germination of Aglaonema affected by relative humidity. HortScience 20:142-143.

Henny, R.J. and J. Chen. 2001. Aglaonema 'Golden Bay'. HortScience 36:1142-1143.

Henny, R.J. and J. Chen. 2008. 'Moonlight Bay' Aglaonema. HortScience 43:1598-1599.

Henny, R.J. and J. Chen. 2009. 'Key Lime' Aglaonema. HortScience 44:1767-1768.

Henny, R.J. and J. Chen. 2010. 'Scenic Bay' Aglaonema. HortScience 45:1281-1282.
Henny, R.J., J. Chen, T.A. Mellich, and M.S. Brennan. 2008. 'Mondo Bay' Aglaonema. HortScience 43:1900-1901.

Henny, R.J., J. Chen, and D.J. Norman. 2003. Aglaonema 'Diamond Bay' and 'Emerald Bay'. HortScience 38:1446-1447.

Henny, R.J., R.T. Poole, and C.A. Conover. 1988. 'Stripes' Aglaonema. HortScience 23:920921.

Henny, R.J., R.T. Poole, and C.A. Conover. 1992a. 'Silver Bay' Aglaonema. HortScience 27:1238.

Henny, R.J., R.T. Poole, and C.A. Conover. 1992b. 'Flamingo' Aglaonema. HortScience 27:1139.

Royal Horticultural Society. 1995. The Royal Horticultural Society's colour chart. 3rd Ed. Royal Hort. Soc., London, UK.

Smith, C.N. and E.F. Scarborough. 1981. Status and development of foliage plant industries, p. 1-39. In: Joiner, J. (ed.). Foliage plant production. Prentice-Hall, Englewood Cliffs, NJ. 